\title{
Do terapêutico e da cidadania: leituras sobre discursos e práticas
}

Mériti de Souza

Neste artigo são problematizadas as relações entre a cidadania e a prática terapêutica no bojo da reforma psiquiátrica. De forma especifica, analisa-se o pressuposto de que o atendimento terapêutico deve se fazer acompanhar do reconhecimento da condição de cidadão daquele que apresenta sofrimento psíquico. O trabalho terapêutico demanda fazeres e saberes calcados em concepções de subjetividade não restritas à de sujeito.

Palavras-chave: Terapêutico, cidadania, sujeito, clínica 


\section{Introdução}

Nos últimos anos, a preocupação dos psicólogos em construir teorias e práticas voltadas à melhoria e à ampliação do atendimento oferecido à população tem assumido contornos inequívocos no Brasil. Essa preocupação tem se intensificado e pontuado a inserção crítica desses profissionais no campo da saúde mental, concomitante à busca pela construção de referenciais teóricos e de estratégias de intervenção articulados ao atendimento à população excluída dos consultórios particulares e dos planos privados de saúde. Pode-se supor que essa demanda se alia à crescente disseminação, no país, de atendimentos psicológicos realizados em condições de enquadre não tradicionais, tanto em instituições de saúde e de ensino quanto em comunidades, dentre outros.

O interesse por essas questões se consolidou pelo fato de a nossa experiência profissional haver se efetivado, de forma preponderante, nos atendimentos realizados em locais como escolas, creches, centro de atenção psicossocial. As atividades que realizamos envolveram diferentes procedimentos nas intervenções ao longo dos anos e nos levavam a acompanhar as análises e debates realizados acerca desses atendimentos. Assim, constantemente estávamos repensando as intervenções e as teorias oferecidas pela psicologia e pela psicanálise para realizar o trabalho com enquadre não tradicional.

Dentre as questões envolvidas nesse debate, podemos verificar que a maioria dos trabalhos realizados no campo da saúde pública, em instituições ou em comunidades, adota o pressuposto de que o atendimento terapêutico se deve fazer acompanhar do reconhecimento da condição de cidadão daquele que apresenta sofrimento mental. Nessa perspectiva, a cidadania é entendida como associada à prática terapêutica, ou, no mínimo, como coadjuvante das estratégias que produzem essa prática.

Frente a tais questões, perguntamos como lidar com o sofrimento constituído nas experiências idiossincráticas, pois remeter a valores universais propostos pela concepção de cidadania parece-nos não ser suficiente para lidarmos com a singularidade humana. Assim, Freud 
(1930) nos alertou que não existem regras de ouro com validade universal e que garantam a felicidade quando aplicadas a todos. Mais ainda, Fédida $(1996 ; 1998)$ alerta que o singular anima o trabalho terapêutico em que pese a sua articulação ao universal.

Face ao exposto, a pergunta que nos mobiliza e orienta o presente artigo é sobre o pressuposto que acompanha a relação estabelecida entre prática terapêutica e cidadania. Nossa trajetória profissional leva a problematizar essa perspectiva em decorrência das repercussões que ela traz às ações entabuladas em nome do terapêutico e do atendimento àquele que porta sofrimento psíquico.

\section{Modernidade, universalidade, singularidade}

No cenário brasileiro contemporâneo, a maioria dos trabalhos direcionados àquele que vivencia sofrimento mental e desenvolvidos na perspectiva do enquadre não tradicional se assenta na perspectiva da conquista da cidadania e da inclusão social. Assim, encontramos essa premissa partilhada por profissionais envolvidos em atividades que abrangem um leque extenso de conceitos e estratégias de intervenção: reabilitação psicossocial; acompanhamento terapêutico; oficinas de escrita; psicanálise na saúde pública; práticas de desinstitucionalização (Guerra, 2004; Barreto, 1998; Oliveira, 2003; Lobosque, 2003; Pitta, 2001; Ibrahim, 1991; Saraceno, 1999).

Em adição, constatamos que nas últimas décadas essa perspectiva se amplia e assume lugar de destaque em inúmeras instituições de atendimento e, também, nas instituições de formação de profissionais voltados ao trabalho psicológico. Dessa forma, desde ateliês e oficinas em hospitais e centros de atenção psicossocial até atividades com grupos em comunidades vêm adotando o pressuposto de que o acesso à cidadania e à inclusão social se encontra articulado à prática terapêutica. Acreditamos que isso acontece em decorrência da sobreposição entre a extensão do contrato social a grupos e pessoas portadoras de sofrimento mental e os princípios necessários ao trabalho terapêutico. Assim, teríamos a manutenção do pressuposto do sujeito moderno calcado no axioma da razão como parâmetro à constituição subjetiva, bem como do pressuposto do conhecimento centrado na categoria do universal. Em outras palavras, a conquista da cidadania operaria um efeito terapêutico necessário à reorganização subjetiva e cognoscente, pois a conquista desse lugar social, associado ao sujeito universal cognoscente, possibilitaria a assunção da razão a ele inerente, por meio do trabalho de contenção das paixões que assolavam o portador de sofrimento psíquico. 
Acreditamos que essas propostas apresentam uma inserção crítica e preocupações com a melhoria dos atendimentos oferecidos, entretanto elas não relevam aspectos importantes e necessários ao debate sobre essa questão. Dentre esses aspectos, chama-nos atenção a apropriação do conceito de cidadania, conforme preconizado pela concepção moderna de mundo, concomitante à sua associação à prática terapêutica. Dessa forma, faz-se necessário problematizar as concepções elaboradas sobre o homem e, referenciadas no solo moderno, que abrem espaço a essa leitura.

O movimento moderno comportou inúmeras facetas. Não obstante, a concepção do homem como sujeito autônomo, constituído pela razão, ocupa papel de destaque nesse cenário. Assim, o pressuposto instaurado apontava para a efetivação da condição ética e da cognoscente no ato de controle do pathos pelo logos; no trabalho de dissociar sujeito e objeto; na adoção do universal como parâmetro; na restrição da subjetividade à consciência (Bachelard, 1996; Blanché, 1983; Sousa Santos, 1996; Bermam, 1986). Esse solo comum deveria garantir a ascensão das pessoas da condição de súdito à de cidadão, pois era alimentado pela crença da emancipação social como resultante desse processo (Bobbio, 1986; Burdeau, s/d.).

Entretanto, ao acompanhar a intrincada história da consolidação do mundo moderno, é possível verificar que a promessa de progresso e de cidadania não se efetivou conforme os ideais postulados. Podemos sugerir que um dos entraves a essa implantação se associa às contradições endógenas à proposta da emancipação social calcada na concepção idealizada do homem racional e ético, bem como na adoção do pressuposto universal subjacente a essa concepção. Entretanto, é válido pressupor que no cenário atual um amplo setor profissional vinculado ao trabalho com a saúde mental estabelece a relação entre prática terapêutica e conquista da cidadania.

\section{Prática terapêutica, sofrimento psíquico e cidadania}

É importante mencionar que a leitura acima realizada conforma os pressupostos de uma linha específica de pensamento que atua no campo da saúde mental no país. Outrossim, podemos localizar no cenário nacional outras propostas que problematizam o dispositivo terapêutico posto a operar nas práticas de saúde mental. Por um lado, na seara da psicanálise, o dispositivo clínico e o enquadre clássico são problematizados desde a geração contemporânea a Freud. Essas discussões alimentam o acirrado debate que ganha corpo em toda a trajetória da história da psicanálise e permanece atual no debate sobre a fronteira entre a de- 
nominada psicanálise legítima e a psicoterapia. No cerne desse debate está presente o pressuposto de que o procedimento standard com o enquadre tradicional definiria a prática psicanalítica. Entretanto, no cenário contemporâneo atinge amplo espectro a idéia de que o acontecer psicanalítico se instala fora do setting tradicional, seja em hospitais ou centros de atenção psicossocial. O que importa nessas situações é a presença do desejo do analista e da ética psicanalítica (Volich, 2000; Freire Costa, 1996; Birman, 1992; Figueiredo, 1997). Por outro lado, movimentos na área de saúde mental - associados à perspectiva da cidadania do portador de sofrimento mental e da sua inclusão social - também ganharam corpo por parte de profissionais psicanalistas que buscam a inserção do atendimento referenciado na ótica do dispositivo clínico e da sua inserção na rede pública de saúde e nos centros de atenção psicossocial. Assim, categorias passaram a ser problematizadas e incorporadas às práticas realizadas na rede pública, como os referenciais da escuta, da clínica ampliada, da clínica psicossocial, dentre outras.

Entretanto, na perspectiva histórica, é necessário acompanhar o debate atual entre profissionais vinculados à denominada saúde mental ou articulados ao cognominado campo clínico. No geral, os primeiros tendem a seguir os parâmetros da inclusão social e dos direitos do portador de sofrimento psíquico. Assim, eles se engajam em movimentos relacionados à luta antimanicomial e nos movimentos pela desinstitucionalização. Os segundos tendem, em sua maioria, a seguir os parâmetros do dispositivo clínico e se preocupam com o atendimento oferecido àquele que sofre no plano psíquico. Ainda, em sua maioria, os últimos tendem a se engajar em atendimentos em hospitais e centros de atenção psicossocial. Acreditamos que esses movimentos, tanto em um campo quanto no outro, não são aleatórios e explicitam uma profunda e séria questão sobre os aportes conceituais e instrumentais relativos à constituição subjetiva, à elaboração do sofrimento, ao dispositivo terapêutico, e às suas relações com a rede social e o paradigma de conhecer moderno. Para aprofundar essa discussão, faz-se necessário discorrer sobre alguns aspectos da história do movimento da antipsiquiatria e da Reforma Psiquiátrica no Brasil.

Conforme se divulga, os movimentos da antipsiquiatria engendraram entre suas ações as denominadas "comunidades terapêuticas" que tinham por objetivo estabelecer um novo olhar sobre a loucura e criar novas redes sociais que sustentam outro lugar para o denominado louco. No Brasil, esse movimento propiciou a criação de comunidades terapêuticas de forma concomitante à constituição do trabalho do acompanhante terapêutico e de outras modalidades de atenção, como alternativa ao internamento hospitalar (Ibrahim, 1991). O movimento de desinstitucionalização e de crítica ao modelo hospitalocêntrico configurou outro grande vetor dessa discussão, que se instalou no âmbito internacional e nacional. Con- 
comitante a essa discussão e como fruto dela, o movimento da Reforma Psiquiátrica ganhou corpo e mobilizou a implementação de ações que buscavam viabilizar a extensão das condições de cidadania ao denominado doente mental que se encontrava asilado em instituições hospitalares.

O debate acerca da Reforma Psiquiátrica Brasileira encontrou o seu ápice com a promulgação da lei 10.216/2001, que foi forjada a partir das Conferências Nacionais de Saúde Mental. Esse contexto abrangeu a criação de diversas leis nos âmbitos federal e estaduais que criaram os Caps - Centros de Atenção Psicossocial, e outros dispositivos direcionados à atenção à saúde mental. Essa mudança possibilitou que o debate sobre a denominada loucura e as intervenções a ela direcionadas ganhasse corpo e operasse como divisor de águas que mobilizava profissionais de diversos matizes teóricos e institucionais (Amarante, 1995, 1994; Delgado, Venâncio, Leal, 1997; Pitta, 2001; Birman, 1992, 2001; Figueiredo, 1997; Freire Costa, 1996; Berlinck e Silva, 2000; Tenório, 2001).

Conforme se discutiu anteriormente, esse movimento histórico serviu de pano de fundo para mudanças no atendimento ao portador de sofrimento psíquico. Tenório (2001) analisa posições no movimento de reforma psiquiátrica, que contrapõem a saúde mental e a clínica. A primeira enfatiza a transformação da dimensão política e social e entende que ela extrapola a dimensão clínica. A outra entende que a constituição da loucura envolve aspectos que apenas a clínica consegue trabalhar. Assim, por um lado, a perspectiva de extensão da cidadania àquele que vivencia sofrimento mental, no geral, se sobrepõe ao trabalho terapêutico e configura um campo teórico e instrumental referenciado no que se denominou de saúde mental. Por outro, a perspectiva do atendimento referenciado na prática clínica mantém, no geral, uma concepção de subjetividade e de método que aliena o atendimento em relação ao contexto social e histórico daquele que vivencia o sofrimento psíquico.

Face a esse cenário, consideramos importante salientar a legítima preocupação da maioria dos profissionais, adeptos dessas diferentes perspectivas, com o trabalho terapêutico. Entretanto, acreditamos que a divisão entre aqueles que advogam a denominada posição da saúde mental e aqueles que advogam a denominada posição da clínica necessita passar por outros crivos. Esse debate necessita ter ampliado o seu escopo para a ordem do terapêutico e suas incidências nas práticas. Assim, Freire Costa (1996) analisa essas abordagens e afirma que a ética da interlocução que orienta em grande medida a denominada posição clínica pode gerar a ênfase no indivíduo em detrimento das perspectivas sociais e políticas. Por seu turno, a ética centrada na ação social que orienta em grande medida a denominada posição clínica pode não trabalhar com os aspectos relacionados à constituição singular do sofrimento psíquico. O dilema está em como 
articular atendimentos orientados por uma posição ética que articule essas duas posições. Entretanto, como vimos anteriormente, a concepção ética se associa a específicas leituras sobre a subjetividade e sobre o conhecimento. Dessa forma, problematizar um aspecto implica necessariamente questionar todos.

\section{Singularidade, experiência e trabalho terapêutico}

Conforme mencionado no começo deste artigo, os atendimentos com enquadres não tradicionais, que desenvolvemos no decorrer de vários anos, levou-nos a questionar o trabalho com a atenção terapêutica, pois as queixas escutadas demandavam o repensar das teorias sobre a constituição subjetiva, o sofrimento psíquico e as estratégias de intervenção.

O trabalho psicológico no atendimento daquele que porta sofrimento psíquico demanda articular a teoria e a intervenção a concepções sobre a constituição psíquica, o sofrimento, a terapéia, a partir de referenciais epistêmicos e ontológicos que extrapolem as concepções modernas de saber e de sujeito. De forma mais específica, o saber centrado no sujeito universal necessita ser problematizado em favor do saber que releva o singular tanto na constituição subjetiva quanto na prática terapêutica.

O singular se articula ao universal à medida que esses planos operam de maneira concomitante. Assim, a prática terapêutica, seja a desenvolvida nos atendimentos individuais, seja aquela desenvolvida nas instituições, articula-se às possibilidades oferecidas pelo contexto social e pelas experiências constitutivas da singularidade humana. A pergunta posta nesse contexto diz respeito a como articular formas de intervenção que possam orientar o trabalho do profissional como produtor de efeitos de subjetivação à medida que o substrato da linguagem e do simbólico, base deste trabalho, se ancora no plano universal. Dito de outra forma, a história da psicologia mostra que o trabalho realizado a partir de pressupostos universais, como a construção de técnicas e de enquadres ou a adoção de categorias, não garante a priori o propósito de uma intervenção terapêutica. Igualmente, o recurso a um referencial calcado no singular também não garante a priori a realização de um trabalho com efeitos de ressignificação da realidade por parte das pessoas nele envolvidas.

$\mathrm{Na}$ perspectiva psicanalítica adstrita ao inconsciente o singular assoma na produção sintomática e de determinado sofrimento que, por sua vez, encontra solo em específico contexto coletivo incrustado no plano cultural e histórico. Essa leitura explicita o trajeto empreendido pelo logos - simbólico e social - no caminho em direção à interioridade do pathos - corpo afetado. Assim, a perspectiva epis- 
têmica estaria subvertida em relação àquela calcada no sujeito moderno, pois pressupõe a produção do saber sobre o sofrimento como construída na relação estabelecida pelos participantes do processo terapêutico.

Reconhecer a presença da relação no plano epistêmico envolve a crítica à primazia da consciência e do aparelho cognoscente que apreende a realidade via sua representação facultada pelo pensamento e pela linguagem. Esse contexto demanda problematizar a configuração do pensamento, da representação e da linguagem, em decorrência da sua relação com o privilégio concedido ao tempo presentificado e a substância, como constitutivos do ser positivado. Em outras palavras, o universal configura-se na linguagem e no ato de simbolizar, entendido como plano privilegiado de representação da realidade. Mais ainda, o universal encarna o conceito e, nesse plano, oferece ancoragem tanto à perspectiva realista, quanto à crítica ao relativismo ético e à configuração do sujeito. Assim, encampar a referência do singular no campo conceitual implica problematizar a representação como modalidade privilegiada de acesso à realidade e de produção do pensamento e da linguagem no processo de subjetivar. Nessa senda, a demanda pelo trabalho com o singular pode recair, por exemplo: na busca por um plano de imanência pré-conceitual; no ato de incorporar o plano do negativo à subjetividade configurada como sujeito não idêntico; no reconhecimento de um plano não cognoscível, avesso à representação e à simbolização.

A partir desse contexto, não obstante os caminhos divergentes que os conceitos de cidadania e de clínica encampam, eles recobrem um universal. Assim, o deslizamento do conceito cidadania para o conceito clínica opera qual transitividade em relação à assunção do singular na configuração subjetiva e na prática terapêutica?

Nessa perspectiva, podemos problematizar a questão do singular e do universal a partir de outras bases. A título de exemplo, construir conhecimento que se anuncia em condições de explicitar e de viabilizar o acesso à singularidade subjetiva demanda a elaboração de teorias e de estratégias de trabalho que envolvem necessariamente o universal. Isso se dá pela dimensão social e histórica que subsumem o código lingüístico e a prática. Dessa forma, por um lado, o embate ocorre no terreno da representação como a priori que satura a teoria, o simbólico e a linguagem. Acreditamos que não basta dizer adeus ao sujeito moderno e ao enclave da cidadania na saúde mental, e oferecer as boas-vindas a teorias que pressupõem o singular adstrito ao simbólico e à representação. Por outro lado, o debate pode caminhar a partir do questionamento dos pressupostos epistêmicos que sustentam perspectivas binárias, pois excluem a cidadania e o universal da clínica e do singular. Entretanto, a própria disciplinarização do conhecimento, ao isolar as pessoas e seus saberes em nichos de tecnicidade, cria a dificuldade 
para a análise crítica e complexa face ao real. Como menciona Morin (2005a, 2005b), o pensamento complexo encontra-se inviabilizado na sociedade contemporânea, pois o saber científico encontra-se esfacelado em disciplinas e os modelos teóricos hegemônicos advogam a dissociação de umas em relação às outras.

O trabalho com o sofrimento psíquico articulado à transdisciplinaridade é proposta assumida por Fédida (1998). Esse referencial propicia a elaboração de um campo ético e discursivo comum em torno do qual gravitariam os diversos saberes com seus conceitos, linguagens e objetivos específicos. Para o autor, a disciplinarização do saber dificulta a comunicação e a interação entre os diversos profissionais afeitos ao trabalho com o sofrimento, o que demanda a transdisciplinaridade como via de superação.

Em decorrência do exposto, para além da análise dirigida à sobreposição entre conquista da cidadania e efeito terapêutico, interessa-nos problematizar a produção de um campo discursivo e ético que sustente o trabalho com o portador de sofrimento psíquico. Para tanto, faz-se necessário reconhecer a presença no cenário nacional do grande percentual de profissionais e pesquisadores articulados em torno de teorias e práticas ancoradas tanto no conceito de cidadania quanto no de clínica. Ainda, supomos que autorizar um campo específico de saber como apto a responder às demandas postas pelo atendimento ao portador de sofrimento psíquico não contempla a complexidade dos aspectos institucionais, políticos, históricos, subjetivos e sociais postos pelo problema.

O trabalho crítico envolve o pensamento complexo e o luto pela disciplinarização que sustenta referenciais identitários teóricos e profissionais. Esse pressuposto necessita, para a sua implementação, que o terapeuta (seja o psicólogo, o psiquiatra, o fisioterapeuta, dentre outros) ocupe um lugar de suportabilidade frente ao não-saber sobre o sofrimento do outro e sobre o seu próprio sofrimento.

“A terceira margem do rio" é o título de sugestiva obra de Guimarães Rosa que nos descentra e nos assombra, como só os habitantes transgressores da língua o sabem fazer. Habitar a condição subjetiva de oscilar na correnteza e não sedimentar nas margens. Para alguns, a terceira margem se associa a indefinições, incertezas, impossibilidades. Para outros, pode implicar o convívio com o devir e com a dúvida que impele o pensamento e a ação. $\mathrm{O}$ artigo em questão segue esse itinerário e não oferece respostas às demandas erigidas tanto pelo conhecimento do sujeito cognoscente quanto pelo desejo ávido de completude. Antes, apresenta nosso percurso e inquietações face ao trabalho terapêutico e perante as reflexões produzidas a partir das nossas experiências. Ao terminar sem concluir, convidamos o leitor a nos acompanhar nessa jornada, e a considerar o imponderável no cotidiano. 


\section{Referências}

Amarante, P. (Org.). Psiquiatria Social e Reforma Psiquiátrica. Rio de Janeiro: Editora Fiocruz, 1994.

. Loucos pela vida: a trajetória da Reforma Psiquiátrica no Brasil. Rio de Janeiro: Panorama/ENSP, 1995.

Bachelard, G. A formação do espírito científico. Rio de Janeiro: Contraponto, 1996.

Blanché, R. A ciência atual e o racionalismo. Lisboa: Res Editora, 1983.

Barretto, K.D. Ética e técnica no Acompanhamento Terapêutico: andanças com Dom Quixote e Sancho Pança. São Paulo: Unimarco, 1998.

Berman, M. Tudo que é sólido desmancha no ar - A aventura da Modernidade. São Paulo: Companhia das Letras, 1986.

Berlinck, M.T.; Silva, M.R. Por uma política de saúde mental mais psicoterapêutica. 2000. Disponível em: <http//www.estadosgerais.org/gruposvirtuais berlinck manoel_tosta_rodrigues_moises_silva_por uma política.shtml $>$. Acesso em: 10 nov.2007. Birman, J. A cidadania tresloucada. In: Bezerra, B.; Amarante, P. (Orgs.). Psiquiatria sem hospício. Rio de Janeiro: Relume-Dumará, 1992.

. Despossessão, saber e loucura: sobre as relações entre psicanálise e psiquiatria hoje. In: Quinet, A. (Org.). Psicanálise e psiquiatria: controvérsias e convergências. Rio de Janeiro: Marca d'Água, 2001.

BobBio, N. O futuro da democracia: uma defesa das regras do jogo. Rio de Janeiro: Paz e Terra, 1986.

Burdeau, G. O Liberalismo. Portugal: Publicações Europa-América, s/d.

Delgado, P.G; Venancio, A.T.; Leal, E.M. (Orgs.). O campo da atenção psicossocial. Rio de Janeiro: Te Corá, 1997.

FÉDIDA, P. O sítio do estrangeiro - a situação psicanalítica. São Paulo: Escuta, 1996.

. De uma psicopatologia geral a uma psicopatologia fundamental. Nota sobre a noção de paradigma. Revista Latinoamericana de Psicopatologia Fundamental, São Paulo, v. I, n. 3, p. 107-121, set.1998.

Figueiredo, A.C. Vastas confusões e atendimentos imperfeitos: a clínica psicanalítica no ambulatório público. Rio de Janeiro: Relume-Dumará, 1997.

Freire Costa, J. Violência e psicanálise. Rio de Janeiro: Graal, 1986.

. As éticas da psiquiatria. In: Figueiredo, A.C. e Silva Filho, J.F. (Orgs.). Ética e saúde mental. Rio de Janeiro: Topbooks, 1996.

Freud, S. (1930). El malestar en la cultura. Biblioteca Nueva: Madrid, 1973. 
Guerra, A.M.C. Reabilitação psicossocial no campo da reforma psiquiátrica. Revista Latinoamericana de Psicopatologia Fundamental, São Paulo, v. VII, n. 2, p. 83-92, jun.2004.

Guimarães Rosa, J. A terceira margem do rio. In: Primeiras estórias. Rio de Janeiro: Nova Fronteira, 2001.

IBrahim, C. Do louco à loucura: o percurso do auxiliar psiquiátrico no Rio de Janeiro. In: Equipe de Acompanhantes Terapêuticos do Hospital dia A Casa (Org.). A rua como espaço clínico. São Paulo: Escuta, 1991.

Lobosque, A.M. Clínica em movimento: por uma sociedade sem manicômios. Rio de Janeiro: Garamond, 2003.

Morin, E. O Método I: natureza da natureza. Porto Alegre: Sulina, 2005a.

. O Método II: a vida da vida. Porto Alegre: Sulina, $2005 \mathrm{~b}$.

Oliveira, I.M.A. As inscrições de um corpo - considerações sobre uma Oficina de Escrita com toxicômanos num centro de recuperação. Revista Latinoamericana de Psicopatologia Fundamental, São Paulo, v. VI, n. 2, p. 114-125, jun.2003.

Pitta, A. (Org.). Reabilitação psicossocial no Brasil. São Paulo: Hucitec, 2001.

SARACENo, B. Libertando identidades: da reabilitação psicossocial à cidadania possível. Rio de Janeiro: TeCorá, 1999.

Sousa Santos, B. Pela mão de Alice. O social e o político na pós-modernidade. São Paulo: Cortez, 1996.

TENÓRIO, F. A psicanálise e a clínica da reforma psiquiátrica. Rio de Janeiro: Rios Ambiciosos, 2001.

Volich, M. R. Psicossomática - De Hipócrates à psicanálise. São Paulo: Casa do Psicólogo, 2000.

\section{Resumos}

(De lo terapéutico y de la ciudadanía: lecturas sobre discursos y prácticas)

En este artículo son problematizadas las relaciones entre ciudadanía y práctica terapéutica en el contexto de la reforma psiquiátrica. De forma especifica se analiza el presupuesto de que la atención terapéutica se debe acompañar del reconocimiento de la condición de ciudadano de quien presenta sufrimiento psíquico. El trabajo terapéutico demanda quehaceres y saberes calzados en concepciones de subjetividad no restrictas a la de sujeto.

Palabras clave: Terapéutico, ciudadanía, sujeto, clínica 
(De la thérapie et de la citoyenneté: lectures sur des discours et des pratiques)

Cet article discute les rapports entre la citoyenneté et la pratique thérapeutique au sein de la réforme psychiatrique. Plus exactement, il analyse la supposition qui défend que le traitement thérapeutique devrait être accompagné de la reconnaissance de la condition de citoyenneté du porteur d'une souffrance psychique. Le travail thérapeutique exige des procédés et des connaissances basés sur des concepts de subjectivité qui ne se limitent pas à celui du sujet.

Mots clés: Thérapie, citoyenneté, sujet, clinique

(Therapeutics and citizenship: readings on discourses and practices)

This article focuses on the relationships between citizenship and therapeutic practice as implicit aspects of the recent psychiatric reform. Specifically, the presupposition that therapeutic treatment must be accompanied by the recognition of the patient as a citizen affected by psychic suffering. Therapeutic work demands ways of working and knowing that are based on conceptions of subjectivity that go beyond the subject.

Key words: Therapeutic, citizenship, subject, clinic

Versão inicial recebida em janeiro de 2008 Versão aprovada para publicação em março de 2008

\section{Méritt de Souza}

Doutora em Psicologia Clínica pela Pontifícia Universidade Católica de São Paulo - PUC-SP. (São Paulo, SP, Brasil); pós-doutorado no CES - Centro de Estudos Sociais, da Universidade de Coimbra (Coimbra, Portugal); professora no Departamento de Psicologia da UFSC Universidade Federal de Santa Catarina (Florianópolis, SC, Brasil); membro da Associação Universitária de Pesquisa em Psicopatologia Fundamental (São Paulo, SP, Brasil).

Universidade Federal de Santa Catarina.

Departamento de Psicologia - UFSC

Campus Universitário Trindade

Caixa Postal 476

88040-900 Florianópolis, SC, Brasil

e-mail: meritidesouza@yahoo.com 